\title{
Measurements of alkyl and multifunctional organic nitrates at a rural site in Ontario
}

\author{
J. M. O'Brien, P. B. Shepson, ${ }^{1}$ K. Muthuramu, C. Hao, H. Niki, and D. R. Hastie \\ Department of Chemistry and Centre for Atmospheric Chemistry, York University, North York, Ontario, Canada
}

\author{
R. Taylor and P. B. Roussel \\ Research Division, Ontario Hydro, Toronto, Canada
}

\begin{abstract}
Measurements of alkyl and multifunctional organic nitrates were conducted at a rural site in Ontario during periods with varying levels of photochemical activity. On August 6 and August 21-23, 1992, a total of 17 organic nitrates $\left(12 C_{3}-C_{6}\right.$ alkyl nitrates, $4 C_{2}-C_{4}$ hydroxynitrates and 1,2-dinitrooxybutane) were quantitatively determined in atmospheric samples. The sum of the organic nitrate concentrations was found to be correlated with ozone and ranged from 12 to 140 parts per trillion (volume). The total concentration of organic nitrates measured contributed from 0.5 to $3.0 \%$ to the total odd nitrogen species. On average, the alkyl nitrates represented $82 \%$, the hydroxynitrates $16 \%$, and the dinitrate $2 \%$ of the total measured organic nitrates. Unidentified organic nitrate peaks determined from an organic nitrate selective detector were found to contribuie an additional $0.25 \%$ to the total odd nitrogen budget. The distribution of alkyl and hydroxy nitrates measured was found to be reasonably consistent with computed relative production rates, for photochemically active air masses. Although the inclusion of the multifunctional organic nitrates does not significantly change the measured contribution of these species to $\mathrm{NO}_{\mathrm{y}}$, it is shown that the isoprene nitrates may contribute as much as the combined contribution of all the measured organic nitrates.
\end{abstract}

\section{Introduction}

Over the past several years it has become clear that conditions of elevated tropospheric ozone can often be a regional problem and that ozone concentrations in excess of existing standards can prevail in rural areas relatively far from anthropogenic source regions. In both urban and rural locations in the United States and Canada, ozone concentrations exceed the standards several times each year. Since it is also apparent that anthropogenic emission controls have been less than effective, a more complete understanding of the operative chemistry is needed. Excess ozone is produced photochemically through peroxy radical oxidation of NO to $\mathrm{NO}_{2}$ [cf. Ridley et al., 1992]. The extent to which emissions of $\mathrm{NO}_{\mathrm{x}}$ can influence ozone production downwind from source regions depends on the photochemical processing of $\mathrm{NO}_{\mathrm{x}}$ into less reactive reservoir species that are ultimately lost to the surface via wet or dry deposition. It is thus important to have a complete knowledge of the distribution of the odd nitrogen species as an air mass ages photochemically. The principal components of reactive nitrogen $\left(\mathrm{NO}_{\mathrm{y}}\right)$ and the total $\mathrm{NO}_{\mathrm{y}}$ mixing ratio have now been measured in several field studies of oxidant chemistry. For sampling sites that are far enough removed from $\mathrm{NO}_{\mathbf{x}}$ sources that significant processing has occurred, it has been consistently found that the sum of the known component concentrations (i.e., NO,

\footnotetext{
${ }^{1}$ Now at Purdue University, Departments of Chemistry, and Earth and Atmospheric Sciences, West Lafayette, Indiana.
}

Copyright 1995 by the American Geophysical Union.

Paper number 94JD03247.

0148-0227/95/94JD-03247\$05.00
$\mathrm{NO}_{2}, \mathrm{HNO}_{3}, \mathrm{PAN}$, and particulate nitrate) is less than the measured $\mathrm{NO}_{\mathrm{y}}$ [Fahey et al., 1986; Buhr et al., 1990; Ridley et al., 1990, 1991; Atlas et al., 1992a; Parrish et al., 1993]. The study conducted by Buhr et al. [1990] indicated that the "missing $\mathrm{NO}_{\mathrm{y}}$ " was correlated with the degree of photochemical "aging," leading to the suggestion that organic nitrates and possibly multifunctional organic nitrates, that are produced as a result of hydrocarbon oxidation may contribute significantly. Yet since the alkyl nitrates (that is, those produced from oxidation of alkanes) were first detected in atmospheric samples by Atlas [1988], they have consistently been found to account for no more than $\approx 2 \%$ of the $\mathrm{NO}_{\mathrm{y}}$ [Flocke et al., 1991; Atlas et al., 1992]. However, it is known that $\mathrm{OH}$ reaction with alkenes can produce organic nitrates in significant yields [Shepson et al., 1985; Tuazon and Atkinson, 1990; Muthuramu et al., 1993] and that alkenes represent a significant fraction of the VOC reactivity, measured as $\Sigma\left(\mathbf{k}_{\mathrm{OH}}\right)_{\mathrm{i}} \cdot[\mathrm{VOC}]_{\mathrm{i}}$. The hydroxy nitrates produced from $\mathrm{OH}$ reaction with alkenes have never been quantitatively determined in ambient samples, and thus it remains unclear as to the total contribution of organic nitrates to the $\mathrm{NO}_{\mathrm{y}}$ budget. In addition to the issue of the $\mathrm{NO}_{\mathrm{y}}$ distribution, measurements of individual organic nitrates can be a useful contribution to studies of oxidant chemistry, since identification of the organic nitrates provides information as to the nature of the peroxy radicals involved in ozone production.

In August 1992 a field campaign was mounted in southern Ontario which aimed at understanding oxidant formation in this region and the influence of both anthropogenic and natural precursors to the operative photochemistry. Measurements of speciated volatile organic compounds (VOCs), $\mathrm{CO}$, total peroxy radicals, $\mathrm{NO}, \mathrm{NO}_{2}, \mathrm{NO}_{\mathrm{y}}, \mathrm{HNO}_{3}$, 
peroxyacetyl nitrate (PAN), organic nitrates (during "intensive" measurement periods) $\mathrm{HCHO}$, and $\mathrm{H}_{2} \mathrm{O}_{2}$ as well as meteorological variables were conducted at a rural site $\approx 150 \mathrm{~km} \mathrm{NE}$ of Toronto, Ontario, between July 15 and August 31, 1992. In this paper we discuss the measurements of alkyl nitrates and the multifunctional organic nitrates that are produced from $\mathrm{OH}$ reaction with ethene, propene, and 1and 2-butene. We also report data for 1,2-dinitrooxybutane, presumably produced from $\mathrm{NO}_{3}$ reaction with 1-butene. The data are discussed in terms of the relative concentrations of the organic nitrates measured, the implied relative concentration of precursor peroxy radicals, and the relationships between the organic nitrates measured and other oxidation products, specifically ozone and PAN, as well as meteorological variables. We find that although the hydroxy nitrates measured do not account for a large fraction of the total organic nitrates, the isoprene nitrates could, depending on the degree of isoprene oxidation occurring in a particular air mass, account for a significant fraction of $\mathrm{NO}_{\mathbf{y}}$.

\section{Experiment}

The measurements described in this work were conducted at a farm near Hastings, Ontario $\left(44^{\circ} 56^{\prime} \mathrm{N}, 77^{\circ} 19^{\prime} \mathrm{W}\right)$, a rural site $\approx 150 \mathrm{~km}$ northeast of Toronto. The site is located on top of a hill in a grassy field about $40 \mathrm{~m}$ above the nearby Trent River (to the west). The site is surrounded by farms with some wooded areas and lies approximately $8 \mathrm{~km} \mathrm{NE}$ of Hastings (population 1007). In this paper we report measurements from two "intensive" measurement periods: August 6, 1992, chosen as a "clean air" period, and August 21-23, a relative oxidant episode period. Organic nitrate samples were collected by pumping air at flow rates ranging from $\approx 275$ to $525 \mathrm{~cm}^{3} / \mathrm{min}$ (due to variability in maximum flows achievable with individual tubes, $400 \mathrm{~cm}^{3} / \mathrm{min}$ average) through a glass tube $(65 \mathrm{~mm} \times 6 \mathrm{~mm}$ OD/2 mm ID, Paxton Scientific Glass, Loveland, Ohio) containing $5 \mathrm{mg}$ of charcoal, as described by Atlas and Schauffler [1991]. Air samples were integrated over the time periods 0200-0900, 0900-1200, $1200-1500,1500-1800,1800-2200$, and 2200-0200 (LT) yielding total sample volumes of 55-175 L. The sample flow rate was monitored using calibrated Tylan mass flow meters. The sample air was drawn rapidly through a $10 \mathrm{~cm}$ OD $\times 8.9$ cm ID Pyrex tube (using a box fan at the bottom) that extended to $1 \mathrm{~m}$ above the roof of the sample building, or $\approx 4 \mathrm{~m}$ above the ground. Organic nitrate samples were withdrawn from this manifold through a PFA Teflon filter holder containing 2- $\mu \mathrm{m}$ pore size Teflon filters and then through a short length $(\approx 60 \mathrm{~cm})$ of $1 / 4$-inch Teflon tubing to two sample tubes connected in series (to evaluate the collection efficiency) using swagelock fittings with Teflon ferrules. Because of the very short residence time of the samples in the Pyrex inlet and in the Teflon sampling line, we expect that losses to the inlet surfaces are minimal. Reproducible sampling and measurements of hydroxy nitrates produced in laboratory reaction chamber studies have been conducted in our laboratory using this method [Muthuramu et al., 1993]. Prior to and after use, the cartridges were sealed with Teflon tape and Teflon caps and wrapped in aluminum foil. After sampling, the cartridges were returned to the York University laboratory, where they were extracted. We have found that the organic nitrates are stable on the charcoal collection tubes for a period of at least 21 days [Muthuramu et al., 1993]. The sample tubes were extracted several times with benzene to produce sample extract total volumes of 50-100 $\mu \mathrm{L}$. Two sets of extracts for the front tubes were obtained to verify the extraction efficiency. Blank tubes were handled in a manner identical to the sample tubes, except that ambient air was not sampled. All extracts were cooled to $\approx 0^{\circ} \mathrm{C}$ and then flame-sealed in glass capillary tubes which were stored at $\approx-5^{\circ} \mathrm{C}$ prior to analysis.

To quantitatively determine the organic nitrate concentrations, a 5- $\mu \mathrm{L}$ aliquot of each sample was analyzed by capillary GC using ECD and pyrolysis/luminol chemiluminescence detection [Hao et al., 1994]. A Varian 3300 GC was used, which was equipped with a septum-cooled programmable injector with on-column injection, and used Varian STAR software for peak integration. The GC used a ${ }^{63} \mathrm{Ni}$ electron capture detector heated to $180^{\circ} \mathrm{C}$. The compounds present in the extracts were separated using a $30 \mathrm{~m}$ x $0.53 \mathrm{~mm}$ ID DB-1701 (Restek) capillary column, as described by Muthuramu et al. [1993]. The GC/ECD responds with high sensitivity to the organic nitrates; however, halogenated compounds that are also present in the samples can interfere with unambiguous identification and quantification of the organic nitrates. A luminol-based chemiluminescence detector has been developed [Hao et al., 1994] which responds only to compounds that thermally decompose to yield $\mathrm{NO}_{2}$ and therefore eliminates the interferences posed by other compounds. As the organic nitrates pass out of the ECD, they are pyrolyzed at $350^{\circ} \mathrm{C}$, which quantitatively produces $\mathrm{NO}_{2}$ and other undetected fragments. This $\mathrm{NO}_{2}$ then reacts with luminol and a chemiluminescent signal is recorded using an HP3395 integrator. The following compounds, in order of elution from the column, were contained in a mixed standard: 2-propyl nitrate, 1-propyl nitrate, 2-butyl (and isobutyl) nitrate, 1-butyl nitrate, 3-methyl-2-butyl nitrate, 3-pentyl nitrate, 2-pentyl nitrate, 2-methyl-1-butyl nitrate, 3-methyl1-butyl nitrate, 1-pentyl nitrate, 3-hexyl nitrate, 2-hexyl nitrate, 1-nitrooxy-2-propanol, 2-nitrooxy-ethanol, 2-nitrooxy1-propanol, 3-nitrooxy-2-butanol, 1-nitrooxy-2-butanol, 2-nitrooxy-1-butanol, and 1,2-dinitrooxy butane. The compounds 2-propyl nitrate and isobutyl nitrate were purchased from Aldrich and used without further purification. All other compounds were synthesized and purified using the procedure described by Muthuramu et al. [1993]. In Figure 1 we present several chromatograms: (a) a luminol detector chromatogram of a mixed standard containing 16 organic nitrates, (b) an ECD chromatogram of an atmospheric sample, and (c) a luminol detector chromatogram for the same sample. Prior to analysis the column in the GC was "conditioned" by heating it to a temperature of $220^{\circ} \mathrm{C}$ for 1 hour followed by 2-3 injections of a high-concentration mixed standard ( $\approx 0.5 \mathrm{nmole} /$ compound). Calibration standards were injected for each sample at concentrations closely approximating those in the samples.

Analysis of successive extracts of front, back, and blank sample tubes, and of duplicate samples allows us to evaluate the uncertainties for our measurements. The second (front tube) extract contained, on average, $8 \%$ of the total quantity found for alkyl nitrates and $25 \%$ of the total for the multifunctional nitrates. Recent experiments indicate that as much as $15 \%$ of the total of the hydroxy nitrates can be found 


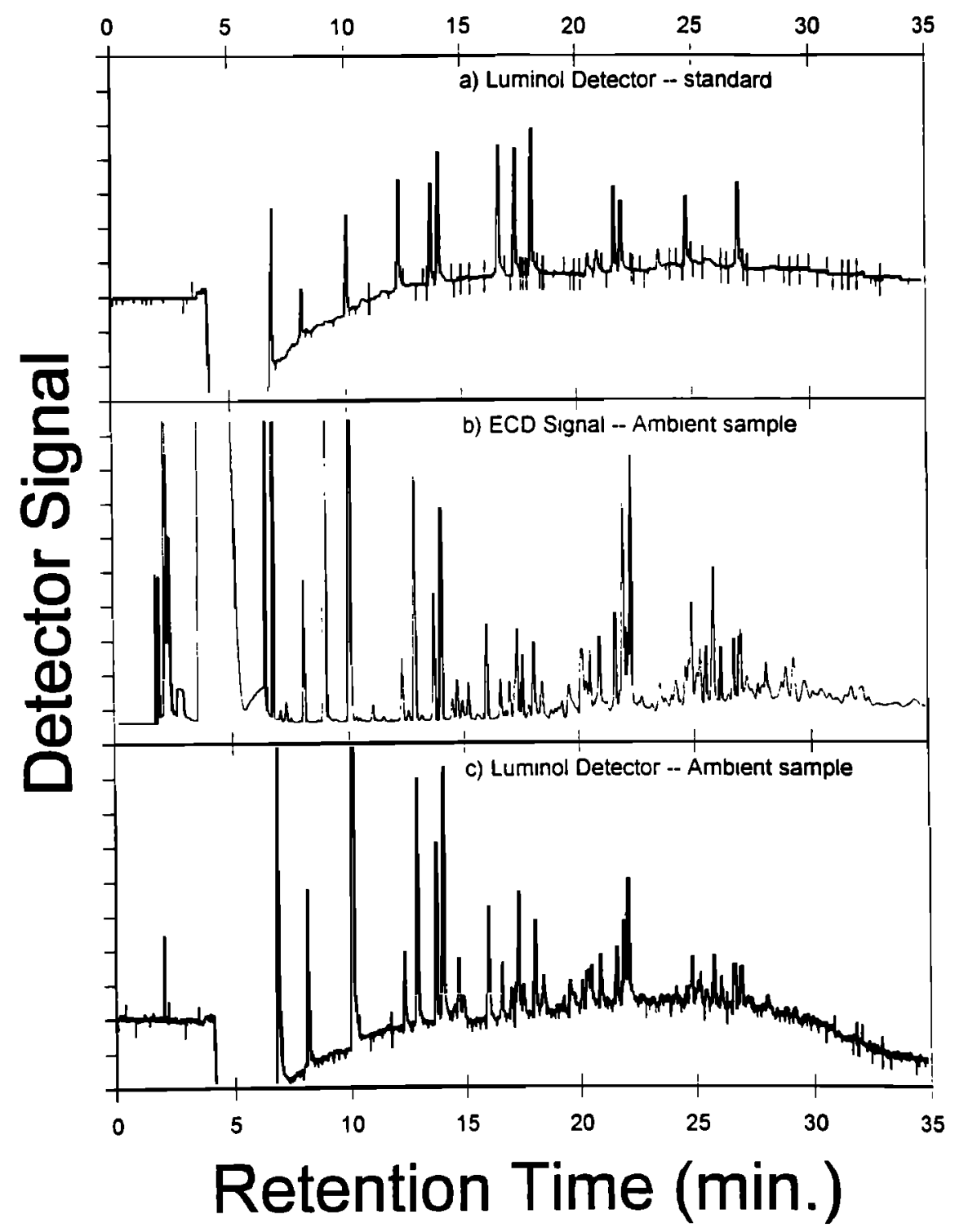

Figure 1. Sample chromatograms for electron capture, and luminol detectors.

in a subsequent third extract using a more polar solvent, acetone. However, this procedure was not used for the field samples. Therefore the hydroxy nitrate concentrations determined may have a systematic error $(-)$ of up to $15 \%$ because of nonperfect extraction efficiency. The quantities present in the two extracts were added together for quantitation. Blank cartridges yielded no quantifiable organic nitrates. The back cartridges were found to contain $\leq 1.5 \%$ of the total quantity of alkyl nitrates (not including 2-propyl nitrate) and an average of $9 \%$ of the total for the multifunctional nitrates (probably representing contamination). The more volatile 2-propyl nitrate had an average breakthrough of $13 \%$, due to the fact that the samples were collected at ambient temperatures. Attempts to collect samples at lower temperatures resulted in water condensation in the sample intake lines, which may adversely affect the collection of the hydroxy nitrates, as they have relatively high Henry's law constants [Kames and Schurath, 1992]. Duplicate analysis of the same sample gave an average difference of $5 \%$ for the alkyl nitrates and $22 \%$ for the multifunctional nitrates. Because some of the samples were below the detection limit for the luminol-based detector, the concentrations reported are those obtained using the ECD. On average, the ECD and luminol detector concentrations agreed to $\approx \pm 22 \%$. Although we paid particular attention to the conditioning of the GC column (especially for the multifunctional nitrates, as per Muthuramu et al. [1993]) we estimate an absolute uncertainty of $\pm 20 \%$ for the alkyl nitrate and $+40 /-30 \%$ for the multifunctional nitrate determinations.

During the 1992 Southem Ontario Oxidants Study (SONTOS), organic nitrates were measured during declared "intensive" measurement periods. In this paper we discuss measurements conducted on August 6, 1992, a day for which air arriving at the site represented relatively clean background continental air. We also discuss measurements conducted during the period August 21-23, 1992, a period characterized by a high-pressure system with flow from anthropogenic source regions to the southwest, including Toronto and anthropogenic sources in southwestem Ontario and the U.S. midwest, under relatively high oxidant concentrations. 


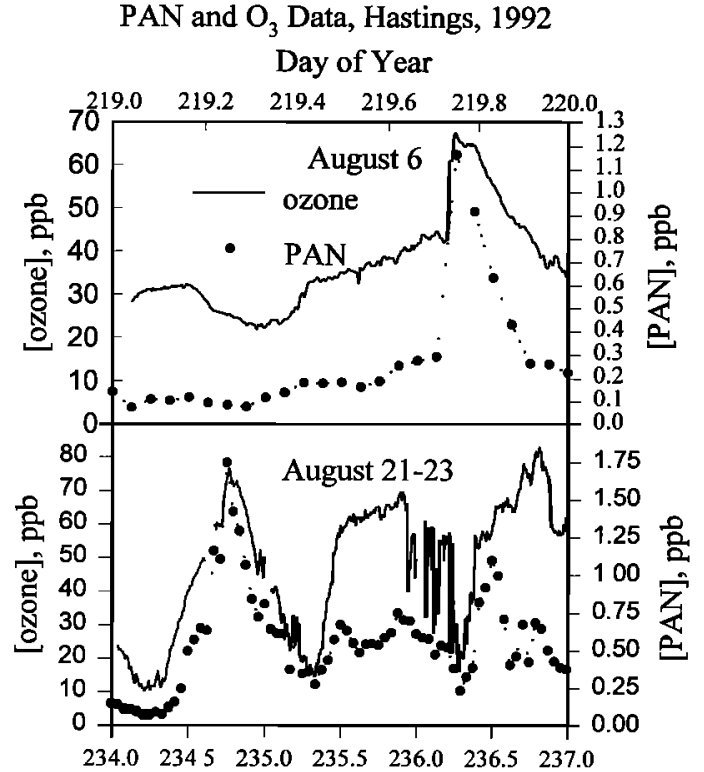

Day of Year

Figure 2. Ozone and peroxyacetyl nitrate (PAN) concentrations observed for August 6 and 21-23, 1992.

\section{Results and Discussion}

\section{Observed Concentrations}

Samples were obtained 6 times daily on August 6 and from August 21 to 23, 1992. For reference the observed ambient ozone (measured using a Dasibi model 1003-AH UV absorption $\mathrm{O}_{3}$ monitor) and PAN (measured as described by Shepson et al. [1992]) concentrations for these two periods are presented in Figure 2. For August 6 the 48-hour back trajectories indicated that the air arriving at Hastings was from the northwest for endpoints in the morning but shifted to westerly for the afternoon. The ozone and PAN data shown in Figure 2 (top) are representative of clean background air, with an $\mathrm{O}_{3} / \mathrm{PAN}$ ratio of $\approx 180$, up to $1800 \mathrm{LT}$. However, at 1800 a considerably more polluted air mass impacted on the site, as witnessed by large and rapid increases in PAN and ozone, and other indicators of anthropogenic pollution, e.g., $\mathrm{NO}_{\mathrm{x}}$ and anthropogenic VOCs. In this air mass the $\mathrm{O}_{3} / \mathrm{PAN}$ ratio decreased to $\approx 60$, more representative of urban air [Shepson et al., 1992]. The back trajectories indicated flow from the southwest at that time. Up to that point the organic nitrate concentrations and distribution probably reflect the impact of multiday atmospheric processing during long-range transport to the site. In Figure 3 we present a plot of the total concentration of the $\mathrm{C}_{3}-\mathrm{C}_{6}$ alkyl nitrates, the total for the $\mathrm{C}_{2}-$ $\mathrm{C}_{4}$ hydroxy nitrates, and the observed concentration of the dinitrate. The organic nitrate concentrations observed before the plume impaction were very low, the alkyl nitrate and total organic nitrate concentrations at noon being only $\approx 10$ and 14 $\mathrm{ppt}$, respectively. The concentration of $\mathrm{C}_{3}$ and $\mathrm{C}_{4}$ alkyl nitrates was only $\approx 5 \mathrm{ppt}$, not much higher than those observed at Mauna Loa, Hawaii [Atlas et al., 1992b], where the $C_{3}$ and $\mathrm{C}_{4}$ organic nitrates were present at an average concentration of 2.9 pptv. Near the time of the observed plume impaction, the sum of the alkyl nitrate concentrations increased to $\approx 50$ parts- per-trillion (by volume, pptv), the hydroxy nitrates to $\approx 20$ pptv, and the dinitrate to $\approx 2 \mathrm{pptv}$. It should be noted that the contribution of the hydroxy nitrates to the total is largest near 1800 and then begins to decrease. This is consistent with the likelihood that the hydroxy nitrates have larger dry deposition velocities than the alkyl nitrates and are lost relatively faster at night within the nocturnal boundary layer. For relatively aged air masses such as that sampled at midday on August 6, it is not surprising that the hydroxy nitrate concentrations were low, relative to the alkyl nitrates. The fact that the dinitrate concentration was observed to increase near the 1800 plume impaction is difficult to understand, since the air mass was photochemically "young," as indicated by an increase in the ratio $\mathrm{NO}_{\mathrm{x}} / \mathrm{NO}_{\mathrm{y}}$, and the total $\mathrm{NO}_{\mathrm{x}}$, as well as other anthropogenic pollutants [Reid et al., 1994], and thus had not experienced nighttime (i.e., $\mathrm{NO}_{3}$ ) chemistry.

During the period August 21-23, with flow consistently from the southwest, the meteorological conditions were typical of those yielding relatively higher concentrations of oxidants: light winds, hazy conditions, and higher temperatures. On August 23 the surface ozone concentration reached $82 \mathrm{ppb}$. The ozone and PAN data shown in Figure 2 (bottom) indicate substantial day/night modulation due to daytime photochemical production and nighttime loss by dry deposition under the inversion layer. As temperatures were relativley high during this period, resulting in short PAN thermal lifetimes, PAN concentrations are a good indication of the level of local photochemical activity needed to sustain them. Thus considerable local photochemical activity is likely for August 21 (day 234). We note that, as shown in Figure 2 for the night of August 22-23, the air sampled did not always appear to be surface layer air depleted of ozone and PAN, as indicated from apparent short periodic downward fluxes of $\mathrm{O}_{3}$-rich air from aloft. This is related to the fact that the sampling site is at the top of a $\approx 40-\mathrm{m}$ hill. The total concentration of alkyl and hydroxy nitrates for this period is shown in Figure 4. As shown in the Figure, the total concentration of organic nitrates reached a high of $140 \mathrm{ppt}$ in the afternoon of August 21, consistent with the high PAN (and $\mathrm{O}_{3}$ ) concentrations indicating significant local scale photochemical activity. The total organic nitrate concentration was roughly a factor of 10 greater than that observed during

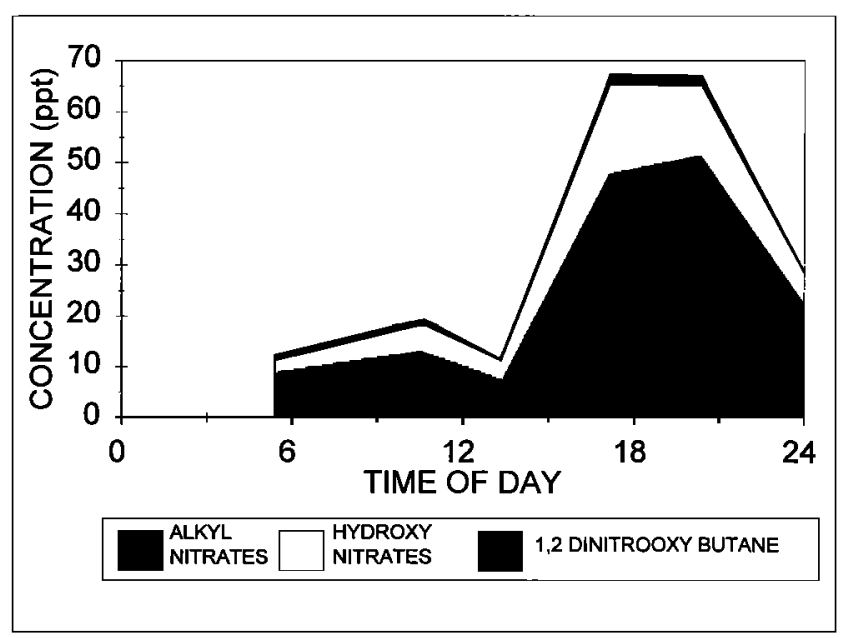

Figure 3. Summed concentrations of each type of organic nitrate measured during clean air intensive, August 6, 1992. 


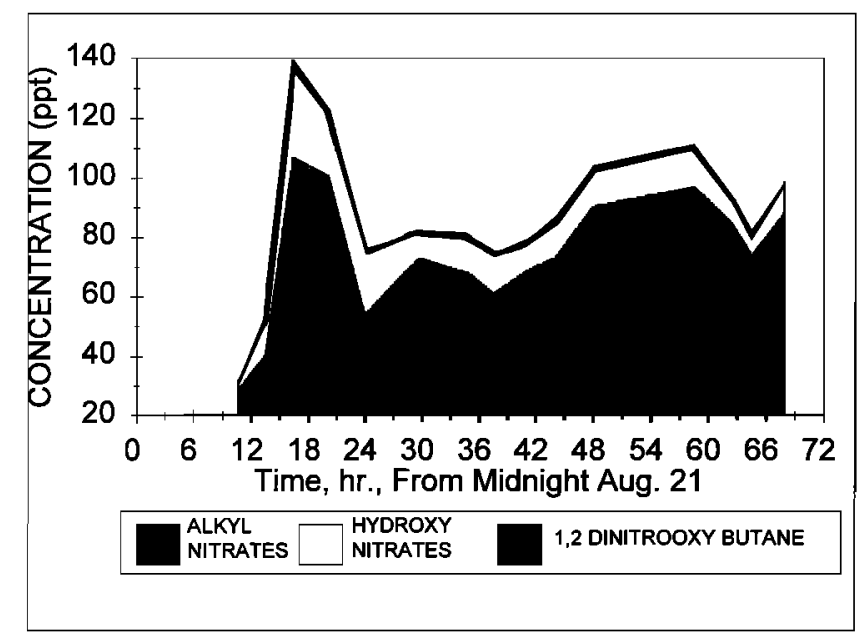

Figure 4. Summed concentrations of each type of organic nitrate measured during oxidant episode, August 21-23, 1992.

midday of August 6, although both were essentially clear-sky days. Given this, it is hard to understand why the hydroxy nitrate contribution to the total was, in fact, less than that observed during midday on August 6 . However, the aerosol $\mathrm{NO}_{3}{ }^{-}$and $\mathrm{SO}_{4}=$ levels were of the order of $5-10$ times those observed for the August 6 case and were unusually high for this area of southern Ontario [Reid et al., 1994]. It is thus possible that a greater fraction of the hydroxy nitrates were adsorbed onto the surface of aerosols. Although our analytical method does not enable quantitative determination of the more volatile methyl and ethyl nitrates which have previously been quantified [Flocke et al., 1991; Grosjean, 1983], we estimate their total concentration to be roughly $14 \mathrm{pptv}$, based on the measured contribution of these compounds to $\mathrm{NO}_{\mathrm{y}}$ made by Flocke et al. [1991] at a forest site in Schauinsland, Germany.

\section{Contribution to $\mathrm{NO}_{\mathrm{y}}$}

For each organic nitrate sample, we calculated the average concentration of $\mathrm{NO}_{\mathrm{y}}$ during the corresponding sampling period. For the purposes of this paper we assume that $\mathrm{NO}_{y} \cong$ "NO ${ }_{x}$ " from the $\mathrm{NO}_{\mathrm{x}}$ channel output from a TECO model $42 \mathrm{~S}$ high-sensitivity chemiluminescent analyzer equipped with a molybdenum reduction catalyst. Measurement data for NO, $\mathrm{NO}_{2}, \mathrm{PAN}, \mathrm{HNO}_{3}$, and the organic nitrates show that the sum of the concentrations of these components is typically within $10 \%$ of the TECO "NO" measurement, and thus this measurement is a reasonable estimate of the actual $\mathrm{NO}_{\mathbf{y}}$. Measurements of these components along with $\mathrm{NO}_{\mathrm{y}}$ via the method (gold tube reduction) corresponding to the current operational definition of $\mathrm{NO}_{\mathrm{y}}$ have produced comparable results [Parrish et al., 1993]; that is, the sum of $\mathrm{NO}, \mathrm{NO}_{2}$, $\mathrm{PAN}$, and $\mathrm{HNO}_{3}$ is typically of the order of $90 \%$ of $\mathrm{NO}_{\mathbf{y}}$. For each sample period, the quantity $\left(\Sigma\left[\mathrm{RONO}_{2}\right]\right) /\left[\mathrm{NO}_{\mathrm{y}}\right]$ is plotted in Figures 5 and 6, for the August 6 and 21-23 periods, respectively. In these figures the solid circles represent all the organic nitrates we were able to identify and quantify using our mixed standard. The open circles in Figure 6 represent the addition of all unidentified organic nitrates that were detected using the organic nitrate-specific detector and quantified using the response factor obtained for 2-butyl nitrate (the response

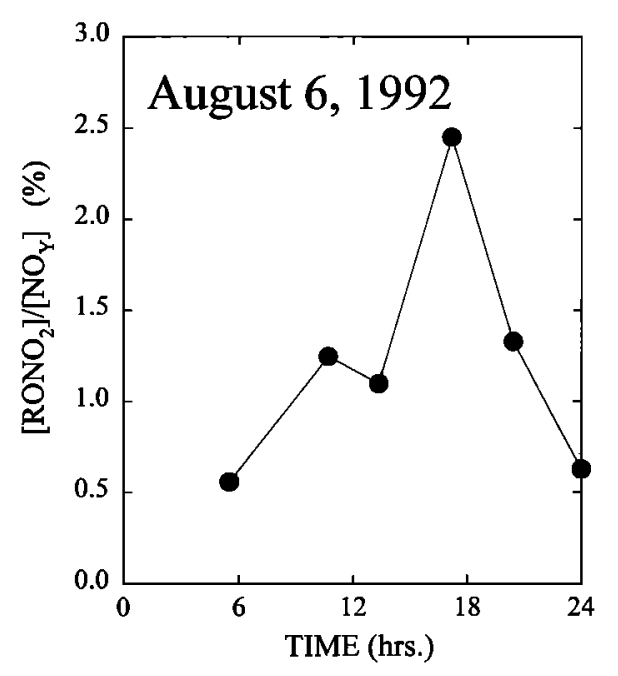

Figure 5. Contribution of organic nitrates to $\mathrm{NO}_{\mathrm{y}}$ for August 6, 1992.

factor has been determined to be the same for all alkyl and hydroxy nitrates, as discussed by Hao et al. [1994]). For August 6 there were no unidentified peaks above the detection limit. As shown in Figure 5, the daytime contribution of all organic nitrates to $\mathrm{NO}_{\mathrm{y}}$ for the clean air case was of the order of $1-1.5 \%$. This value increases to $2.5 \%$ within the plume that reaches the site at 1800 . This is an interesting observation, since although the concentration of all pollutants is high, the air is less "aged," as mentioned above. This is probably an indication that the well-aged but clean air in the

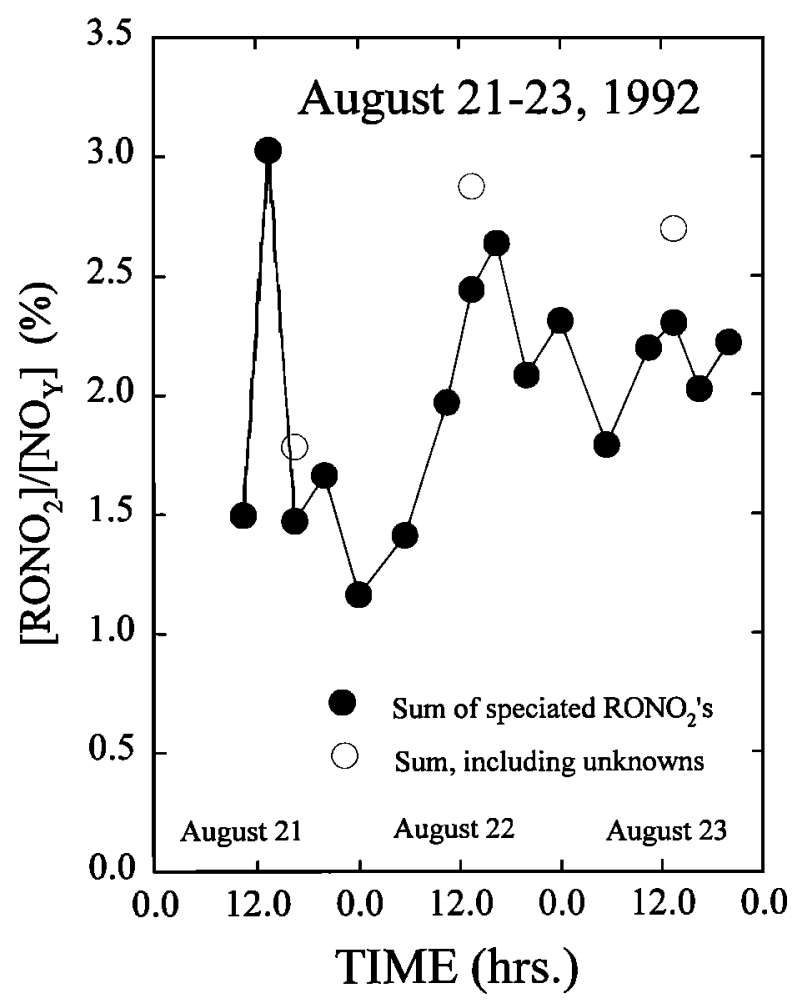

Figure 6. Contribution of organic nitrates to $\mathrm{NO}_{\mathrm{y}}$ for August 21-23, 1992. 
daytime had experienced considerable relative loss of the organic nitrates from the $\mathrm{NO}_{\mathrm{y}} \mathrm{mix}$, through the process of $\mathrm{OH}$ reaction, photolysis, and dry deposition [Roberts, 1990].

As shown in Figure 6, the observed contribution of all quantified organic nitrates to $\mathrm{NO}_{\mathrm{y}}$ for the period August 21-23 was $2-2.5 \%$, for daytime production-dominated conditions. As indicated in the figure, the total contribution to $\mathrm{NO}_{\mathrm{y}}$ increases by a few tenths of a percent by adding all the unidentified peaks from the luminol detector. We estimate that the total would also increase by a few tenths of a percent by including methyl and ethyl nitrate. The total contribution of the organic nitrates we measured, plus methyl and ethyl nitrate, would probably be $\approx 3 \%$, for these daytime, relatively high oxidant conditions. It should be noted, however, that we have not necessarily quantified all organic nitrates; we only determined those that are quantitatively sampled, extracted, and that survive the chromatographic process. The value $2-2.5 \%$ is significantly higher than the range of about 1.0-1.5\% observed (daytime) by Buhr et al. [1990], who measured $\mathrm{C}_{2}-\mathrm{C}_{5}$ alkyl nitrates at a similar site at Scotia, Pennyslvania. Flocke et al. [1991] found that $C_{1}-C_{5}$ alkyl nitrates contribute, on average, between 1 and $2 \%$ in urban and forested regions of Germany, although the contribution was occasionally as high as $7 \%$. Although it appears as though the hydroxy nitrate contribution to the $\mathrm{NO}_{\mathrm{y}}$ budget is small $(\sim 0.4 \%)$, it should be noted that we only quantified four $\mathrm{C}_{2}-\mathrm{C}_{4}$ hydroxy nitrates, and not those likely produced from other reactive alkenes, such as isobutene. Some of them (e.g., those from isobutene) may, however, be included in our total area measurements (i.e., the open circles in Figure 6). It is believed that $>\mathrm{C}_{8}$ alkyl nitrates and $>\mathrm{C}_{4}$ hydroxy nitrates may be at least partially aerosol bound [Roberts, 1990]. Measurements of these lower volatility organic nitrates (including perhaps those from isoprene and terpenes) have yet to be conducted, and they may represent a significant portion of the $\mathrm{NO}_{\mathrm{y}}$ deficit, as the precursor hydrocarbons tend to be quite reactive, and the production yields from the precursor radicals is probably large. This is discussed further below for the case of isoprene.

\section{Relationships to the Precursor Peroxy Radicals}

Because ozone and the organic nitrates are both produced from reaction of peroxy radicals with NO, we expect a correlation between the concentrations of the two, as discussed by Flocke et al. [1991], particularly for photochemically active air masses. Specifically, while ozone is produced as a result of reaction (R1a), below, where " $\mathrm{RO}_{2}$ " represents all peroxy radicals including $\mathrm{HO}_{2}$, the

$$
\begin{aligned}
\mathrm{RO}_{2} \cdot+\mathrm{NO} & \rightarrow[\mathrm{ROONO}]^{*} \rightarrow \mathrm{RO} \cdot+\mathrm{NO}_{2} \\
& +\mathrm{M} \rightarrow \mathrm{RONO}_{2}
\end{aligned}
$$

competing (R1b) results in organic nitrate production. It is well known that the branching ratio $k_{1 b} / k_{1}$ increases significantly with the size of the organic group $\mathrm{R}$ [Carter and Atkinson, 1989]. As discussed by Flocke et al. [1991], since the rate of (R1a) is equal to the rate of ozone production, a plot of $\left[\mathrm{O}_{3}\right]$ versus $\Sigma\left[\mathrm{RONO}_{2}\right]_{\mathrm{i}}$ yields a slope approximately equal to $\bar{\alpha}$, the average branching ratio for all peroxy radicals (including $\mathrm{HO}_{2}$ and $\mathrm{CH}_{3} \mathrm{O}_{2}$ ) participating in NO oxidation. Since the branching ratio increases as the size of the $\mathbf{R}$ group increases, the slope yields information regarding the average

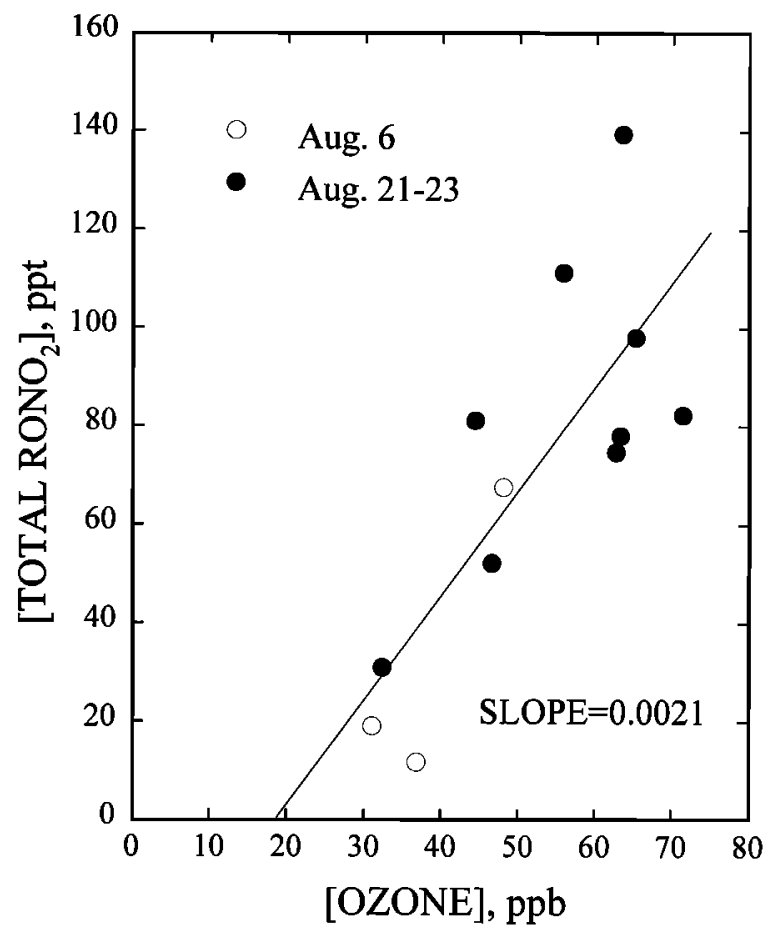

Figure 7. Regression of total $\mathrm{RONO}_{2}$ versus ozone for daytime data.

size of the $\mathrm{R}$ group responsible for the $\mathrm{O}_{3}$ production. The $\Sigma\left[\mathrm{RONO}_{2}\right]_{\mathrm{i}}$ for all samples obtained during the time 0900-1800 for both intensive periods was plotted against the $\mathrm{O}_{3}$ concentration averaged over the corresponding sample period. The results are shown in Figure 7. The average branching ratio determined from the slope is $2.1 \pm 0.5 \times 10^{-3}$, similar to the value of $3.0 \times 10^{-3}$ found by Flocke et al. [1991] for Schauinsland, Germany. The data in this figure include samples obtained from relatively aged air masses (i.e., the August 6 case), in which case the organic nitrates and specifically hydroxy nitrates could be impacted by depositional loss. Although the hydroxy nitrates were only $\approx 28 \%$ of the total organic nitrates, the slope is thus probably a lower limit. This is particularly true if there are organic nitrates that do not survive the sampling and chromatographic processes, e.g., the isoprene nitrates, discussed below. The value of the slope obtained is much smaller than the branching ratio for even ethyl peroxy radicals of 0.014 [Atkinson, 1986] and indicates that the dominant $\mathrm{RO}_{2}$ radicals responsible for $\mathrm{O}_{3}$ production are $\mathrm{CH}_{3} \mathrm{O}_{2}$ and $\mathrm{HO}_{2}$ (both of which are believed to have a branching ratio of zero). However, it should be noted that the origin of the $\mathrm{HO}_{2}$ radicals is often from the oxidation of larger hydrocarbons, and that the $\mathrm{HO}_{2}$ radicals cycle, with a chain length of approximately 11.8 for this study [Hastie et al., 1994]. Of interest is the average branching ratio for the organic peroxy radicals. A onedimensional modeling study [Plummer et al., 1994] indicates that on the order of $70 \%$ of the NO oxidations at this site (for the August 6 case) occur via $\mathrm{HO}_{2}$ reaction. Thus the amount of $\mathrm{O}_{3}$ produced via organic peroxy radicals is roughly $30 \%$ that indicated by Figure 7, and the average branching ratio for organic peroxy radicals is then closer to $7 \times 10^{-3}$. This is still consistent with the idea that $\mathrm{CH}_{3} \mathrm{O}_{2}$ radicals are the dominant 
organic peroxy radicals, for the air masses sampled, in agreement with the results of one-dimensional (1-D) model calculations [Plummer et al., 1994]. It should be noted, however, that the value $7 \times 10^{-3}$ may still be a lower limit to the extent that it is possible that not all the organic nitrates, e.g., the isoprene nitrates discussed below, have been detected.

The measured relative distribution of the organic nitrates can provide useful information as to the relative distribution of the precursor organic peroxy radicals, that can then be used for comparison with model computations. The relative abundance of each $\mathrm{RO}_{2}$. radical can be determined, given the known branching ratio $\mathrm{k}_{1 b} / \mathrm{k}_{1}$ and the measured organic nitrate concentration. Specifically, the absolute rate of production for an individual organic nitrate $\mathrm{i}$ is given by $\mathrm{d}\left[\mathrm{RONO}_{2}\right]_{\mathrm{i}} / \mathrm{dt}=$ $\alpha_{i} \cdot\left(k_{1}\right)_{i} \cdot\left[R_{2} \cdot\right]_{i} \cdot[N O]$, and thus $\left[R_{2}\right]_{i}=$ $\left[\mathrm{d}\left[\mathrm{RONO} \mathrm{O}_{2}\right]_{/} / \mathrm{dt}\right] / \alpha_{\mathrm{i}} \cdot\left(\mathrm{k}_{1}\right)_{i} \cdot[\mathrm{NO}]$. For a photochemically active air mass, such as that sampled during the period August 2123 , we assume that the production of organic nitrates dominates over destruction and that the observed relative organic nitrate concentrations are equivalent to the relative production rates. In addition, we assume that the rate constant $k_{1}$ for peroxy radical reaction with NO is the same for all $\mathrm{RO}_{2}$ radicals, as is done in most currently used photochemical models [cf. Stockwell et al., 1990], and that [NO] is the same for each organic nitrate; that is, they are all produced concurrently. Under these conditions the relative $\mathrm{RO}_{2}$. concentrations in the air mass in which the organic nitrates were produced can be calculated from equation (1):

$$
\left[\mathrm{RO}_{2} \cdot\right]_{\mathrm{i}} \propto\left[\mathrm{RONO}_{2}\right]_{i} / \alpha_{\mathrm{i}}
$$

where $\alpha_{i}=\left(k_{1 b} / k_{1}\right)_{i}$. Figure 8 shows the calculated relative abundance of each of the $\mathrm{RO}_{2}$. radicals that are precursors to the organic nitrates measured (numbered as indicated in Table 1), for daytime measurements during the period August 21-23. The results shown in Figure 8 indicate that the relative abundance of $\mathrm{RO}_{2} \cdot$ radicals decreases markedly as the size of the $\mathbf{R}$ group increases (in contrast to the relatively flat organic nitrate production rate profile; see below). This is due to the fact that the abundance of the precursor hydrocarbons decreases as the size of the $R$ group increases to a greater extent than the corresponding increase in the $\mathrm{OH}$ rate constant. The data in Figure 8 also clearly show the relative importance of the hydroxy-peroxy radicals (although we do not have a measurement for the $\mathrm{C}_{2} \mathrm{H}_{5} \mathrm{O}_{2}$ radical). Although we were only able to quantify four hydroxy nitrates, the sum of their corresponding $\mathrm{RO}_{2}$. radical concentrations represents $37 \%$ of the total. These measurements can be used for evaluation of the organic peroxy radical chemistry incorporated in photochemical oxidant models.

\section{Relative Production Rates}

Our measurement data indicate that the hydroxy nitrates do not represent a large component of $\mathrm{NO}_{\mathrm{y}}$ and thus probably

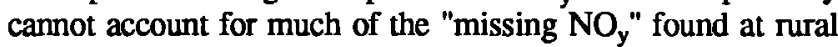
sites such as Scotia, Pennyslvania [Buhr et al., 1990]. However, measurement of the hydroxy nitrates is much more difficult than the alkyl nitrates because of their more polar nature, greater water solubility [Kames and Schurath, 1992], and their tendency to undergo irreversible adsorption on surfaces, such as sampling inlets and chromatographic columns [Muthuramu et al., 1993]. Therefore any systematic analytical errors would likely be in the negative direction. To

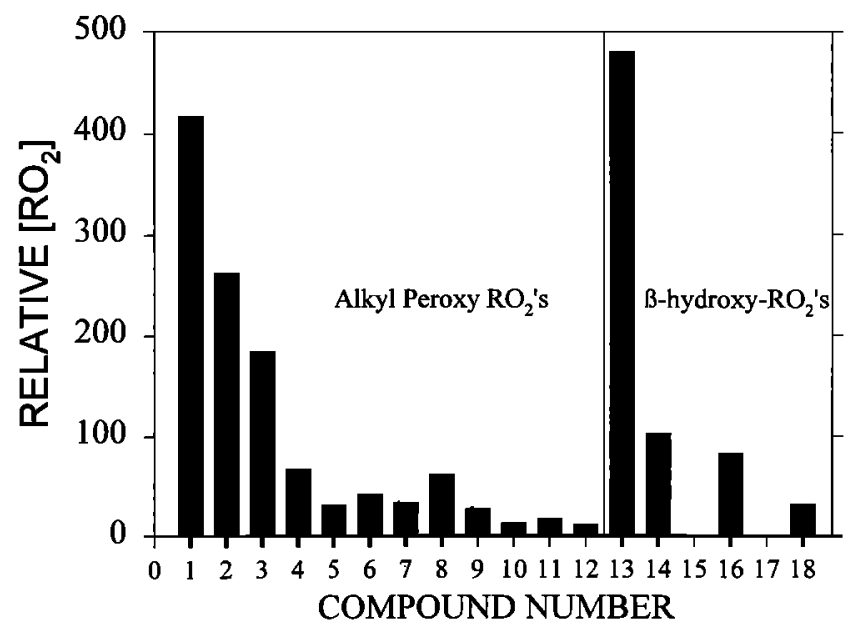

Figure 8. Comparison of the relative concentrations of $\mathrm{RO}_{2}$ radicals produced from $\mathrm{OH}$ reaction with alkanes and alkenes.

aid in evaluation of this possibilty, we can compare the measured concentration distribution for alkyl nitrates and hydroxy nitrates with the computed relative production rates. The production rate of an individual organic nitrate $i$, resulting from $\mathrm{OH}$ reaction with an alkane or alkene, can be computed as shown in equation (2) [Shepson et al., 1993]:

$$
\mathrm{d}\left[\mathrm{RONO}_{2}\right]_{\mathrm{i}} / \mathrm{dt}=\left(\mathrm{k}_{\mathrm{OH}}\right)_{\mathrm{i}} \cdot[\mathrm{NMHC}]_{\mathrm{i}} \cdot[\mathrm{OH}] \cdot\left(\mathrm{RO}_{2} \text { Yield }\right) \cdot \alpha_{\mathrm{i}}
$$

If we assume that the organic nitrates are all produced simultaneously, i.e., the precursor hydrocarbons react with the same effective $[\mathrm{OH}]$, we can calculate a relative formation constant $\beta$ (in units of $s^{-1}$ ), as shown in equation (3):

$$
\beta_{i}=\left(k_{O H}\right)_{i} \cdot[N M H C]_{i} \cdot\left(R_{2} \text { Yield }\right) \cdot \alpha_{i}
$$

where $\left(\mathrm{k}_{\mathrm{OH}}\right)_{\mathrm{i}}$ is the rate constant for $\mathrm{OH}$ abstraction/addition with the appropriate precursor alkane/alkene $\left(\mathrm{NMHC}_{\mathrm{i}}\right)$. The $\mathrm{RO}_{2}$ yield in equation (3) is the fraction of $\mathrm{OH}$ abstractions (alkanes) or $\mathrm{OH}$ additions (alkenes) that yield the specific peroxy radical precursor to $\left(\mathrm{RONO}_{2}\right)_{\mathrm{i}}$. Some of the branching ratios $\alpha_{i}$ have been determined experimentally [Atkinson, 1986; Carter and Atkinson, 1989; Shepson et al., 1985; Muthuramu et al., 1993]. However, for many of the alkenes the branching ratios were estimated because literature information is unavailable. The values used are shown in Table 1. The hydrocarbon concentrations used were those measured at the site during the sampling period. The relative formation rates and the determined concentrations for each organic nitrate (left axis) are shown in Figure 9, for the 1200-1500 period samples taken on August 6, and in Figure 10, for those from August 23, where the compound numbers in the figures refer to organic nitrates, as indicated in Table 1. The values for the relative production rates were scaled so that they could be readily compared with respect to the relative magnitudes of the measured concentrations. As shown in these two figures, there is reasonable correlation between the relative formation rates and the relative measured concentrations. In addition, the relative amounts of the alkyl nitrates and hydroxy nitrates actually measured compares reasonably well with the computed relative formation rates; that is, the amount of hydroxy nitrates found (relative to the alkyl nitrates) is comparable to what was expected. The correlation between measured and computed relative 
Table 1. Kinetic Data Used for Calculation of Relative Organic Nitrate Production Rates

\begin{tabular}{|c|c|c|c|c|}
\hline $\begin{array}{l}\text { Compound } \\
\text { Number }\end{array}$ & Organic Nitrate & $\mathrm{k}_{\mathrm{OH}}^{2}$ & $\mathrm{RO}_{2}$ Yield $^{\mathbf{b}}$ & $\begin{array}{c}\text { Branching } \\
\text { Ratio }\left(k_{1 b} / k_{1}\right)\end{array}$ \\
\hline 1 & 2-propyl nitrate & $1.15 \times 10^{-12}$ & 0.693 & 0.042 \\
\hline 2 & 1-propyl nitrate & $1.15 \times 10^{-12}$ & 0.307 & 0.02 \\
\hline 3 & 2-butyl nitrate & $2.54 \times 10^{-12}$ & 0.853 & 0.09 \\
\hline 3 & isobutyl nitrate & $2.34 \times 10^{-12}$ & 0.233 & 0.036 \\
\hline 4 & 1-butyl nitrate & $2.54 \times 10^{-12}$ & 0.147 & 0.036 \\
\hline 5 & 3-pentyl nitrate & $3.94 \times 10^{-12}$ & 0.354 & 0.131 \\
\hline 6 & 2-pentyl nitrate & $3.94 \times 10^{-12}$ & 0.551 & 0.129 \\
\hline 7 & 1-pentyl nitrate & $3.94 \times 10^{-12}$ & 0.095 & 0.052 \\
\hline 8 & 3-methyl-2-butyl nitrate & $3.90 \times 10^{-12}$ & 0.270 & 0.141 \\
\hline 9 & 2-methyl-1-butyl nitrate & $3.90 \times 10^{-12}$ & 0.094 & 0.056 \\
\hline 10 & 3-methyl-1-butyl nitrate & $3.90 \times 10^{-12}$ & 0.047 & 0.056 \\
\hline 11 & 3-hexyl nitrate & $5.61 \times 10^{-12}$ & 0.524 & 0.230 \\
\hline 12 & 2-hexyl nitrate & $5.61 \times 10^{-12}$ & 0.406 & 0.209 \\
\hline 13 & 2-nitrooxyethanol & $8.52 \times 10^{-12}$ & 1.00 & $0.01^{8}$ \\
\hline 14 & 1-nitrooxy-2-propanol & $2.63 \times 10^{-11}$ & $0.333^{c, d}$ & $0.019^{h}$ \\
\hline 15 & 2-nitrooxy-1-propanol & $2.63 \times 10^{-11}$ & $0.618^{c, d}$ & $0.022^{h}$ \\
\hline \multirow{2}{*}{16} & 3-nitrooxy-2-butanol & $5.64 \times 10^{-11}$ (cis) & $0.90^{\circ}$ & $0.037^{i}$ \\
\hline & & $6.40 \times 10^{-11}$ (trans) & $0.90^{\mathrm{e}}$ & $0.037^{1}$ \\
\hline 17 & 1-nitrooxy-2-butanol & $3.14 \times 10^{-11}$ & $0.315^{\mathrm{de}}$ & $0.037^{8}$ \\
\hline 18 & 2-nitrooxy-1-butanol & $3.14 \times 10^{-11}$ & $0.585^{\mathrm{de}}$ & $0.037^{8}$ \\
\hline 19 & isoprene nitrates & $1.01 \times 10^{-10}$ & 1.00 & $0.12^{1}$ \\
\hline
\end{tabular}

These are room temperature rate constants, in units of $\mathrm{cm}^{3}$ molecule ${ }^{-1} \mathrm{~s}^{-1}$, for the reaction of $\mathrm{OH}$ radicals with parent hydrocarbons [from Alkinson, 1989].

b For $\mathrm{C}_{3}-\mathrm{C}_{6}$ alkyl nitrate production, the $\mathrm{RO}_{2}$ yield from respective alkanes was calculated as described by [Atkinson 1987].

${ }^{c}$ Assuming 5\% of $\mathrm{OH}$ reaction by $\mathrm{H}$-atom abstraction [see Atkinson, 1989].

d Assuming 65\% of $\mathrm{OH}$ addition to the terminal carbon [see Alkinson, 1989].

- Assuming $10 \%$ of $\mathrm{OH}$ reaction by $\mathrm{H}$-atom abstraction [see Atkinson, 1989].

f The branching ratios for formation of $\mathrm{C}_{3}-\mathrm{C}_{6}$ alkyl nitrates are either experimentally obtained values or estimated values from Carter and Atkinson [1989].

8 Estimated value.

bhepson et al. [1985].

${ }^{i}$ Muthuramu el al. [1993].

${ }^{\top}$ Tuazon and Alkinson [1990].

formation rates is better for the August 23 period. This is to be expected, since the August 23 period represents one in which there is significant local photochemistry occurring, whereas for August 6, the organic nitrate distribution is probably significantly affected by the relative removal rates, as discussed above. As found previously [Shepson et al., 1993], there are some anomolies. There is much more of the 2- and 1-propyl nitrates than expected, assuming that they are produced solely from propane oxidation. The data shown here indicate that this is not a good assumption. It is likely that the smaller alkyl peroxy radicals are also produced in significant yields as a result of the decomposition of larger alkoxy radicals. For example, it has been found by Flocke et al. [1993] that 2-propyl nitrate is produced in significant yields in the $\mathrm{OH}$ oxidation of isopentane. The general mechanism suggested by Flocke et al. to account for this observation involves decomposition of an alkoxy radical to yield a carbonyl compound and an alkyl radical. As an example, this mechanism, which has been discussed by Atkinson and Carter [1991], can account for the production of 1-propyl nitrate via decomposition of the 2-pentoxy radical, produced via (R1a):

$$
\begin{gathered}
\mathrm{CH}_{3} \mathrm{CH}\left(\mathrm{O} \cdot \mathrm{CH}_{2} \mathrm{CH}_{2} \mathrm{CH}_{3} \rightarrow \mathrm{CH}_{3} \mathrm{CH}(\mathrm{O})+\mathrm{CH}_{3} \mathrm{CH}_{2} \mathrm{CH}_{2} \cdot\right. \\
\mathrm{CH}_{3} \mathrm{CH}_{2} \mathrm{CH}_{2}+\mathrm{O}_{2} \rightarrow \mathrm{CH}_{3} \mathrm{CH}_{2} \mathrm{CH}_{2} \mathrm{OO} .
\end{gathered}
$$

$$
\mathrm{CH}_{3} \mathrm{CH}_{2} \mathrm{CH}_{2} \mathrm{OO}+\mathrm{NO} \rightarrow \mathrm{CH}_{3} \mathrm{CH}_{2} \mathrm{CH}_{2} \mathrm{ONO}_{2}
$$

Thus pentane oxidation could contribute to the relatively large concentration of 1-propyl nitrate observed.

An important result from our calculations of the relative formation rates is the result for isoprene nitrates. The yield for

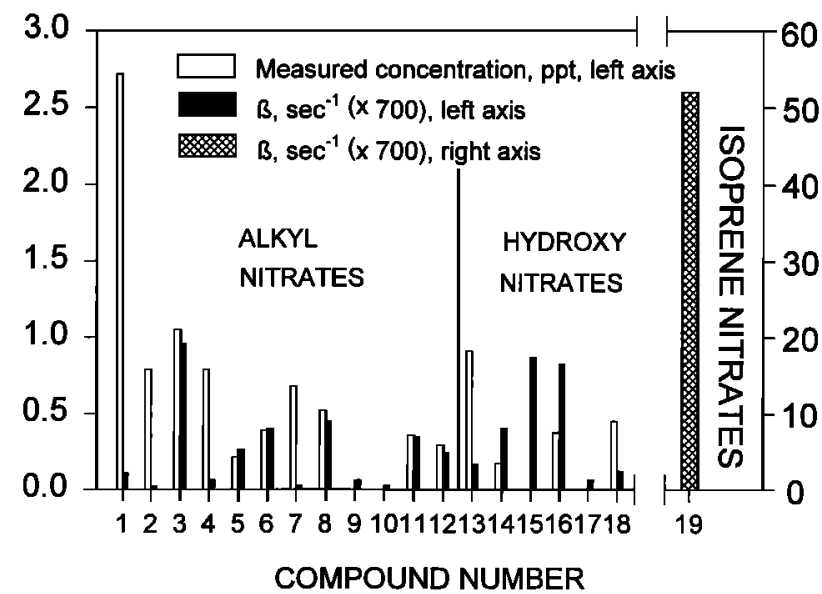

Figure 9. Comparison of the distribution of measured organic nitrate concentration and the computed relative production rates for 1200-1500, August 6, 1992. 


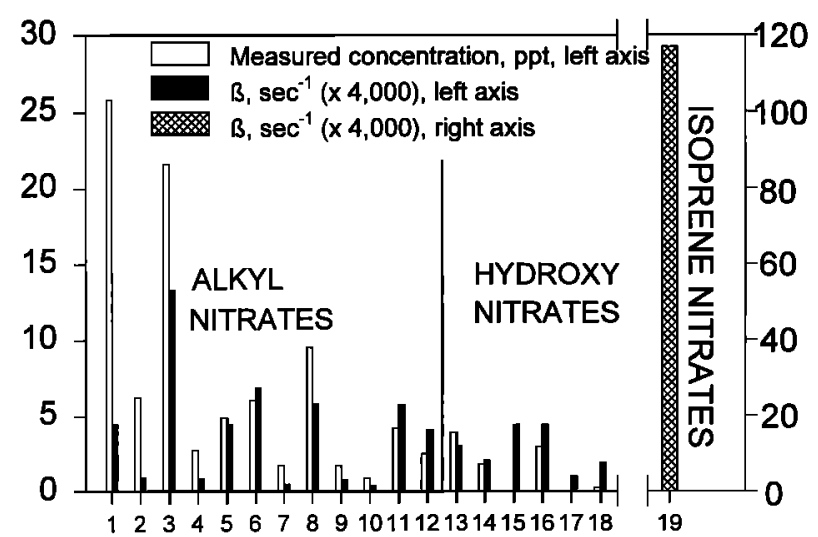

COMPOUND NUMBER

Figure 10. Comparison of the distribution of measured organic nitrate concentrations and the computed relative production rates for 1200-1500, August 23, 1992.

their production, i.e., $\mathrm{k}_{1 \mathrm{~b}} / \mathrm{k}_{1}$, is believed to be large, estimated at $12 \%$ [Tuazon and Atkinson, 1990]. Unfortunately, we were not able to quantitatively measure these compounds, due to some combination of problems associated with their decomposition on the charcoal traps and/or inefficient extraction from the traps. However, isoprene measurements were routinely conducted, and we were thus able to calculate the relative production rate for these compounds. The results are shown in Figures 9 and 10 for the August 6 and 21-23 periods, respectively, as the hatched bar. The calculated relative production rate for hydroxy nitrates from isoprene (right axis) indicates that their contribution exceeded the sum of all other organic nitrates measured, by a factor of 9.6 for August 6 and by a factor of 1.8 for the August 23 measurements. However, this value may be misleading since the measured isoprene concentrations could be significantly impacted by local sources, whereas the chemistry producing the alkyl and other hydroxy nitrates could have taken place, to a significant extent, upwind. On the other hand, we find isoprene concentrations at rural sites just upwind of Toronto to be comparable to those measured at Hastings. Thus the basic conclusion from this calculation, that a substantial fraction of the total organic nitrates (i.e., $>60 \%$ ) could be in the form of the isoprene nitrates for similar rural sites, remains uncompromised by the complication that production of the isoprene nitrates and the alkyl nitrates may not be occurring in the same air mass. It is thus possible that the isoprene nitrates represent a significant fraction of the $\mathrm{NO}_{\mathrm{y}}$ in the air masses sampled. Results from a one-dimensional model simulation of the August 6 case [Plummer et al., 1994] indicate that the total contribution of organic nitrates, including the isoprene nitrates, to the measured $\mathrm{NO}_{\mathrm{y}}$ could be as large as $\approx 7 \%$, for this relatively clean air case. For forest sites at higher temperatures, e.g., in the southeastern United States, the contribution of the isoprene nitrates could be substantial.

\section{Conclusions}

The results from this study are consistent with the findings of other studies which indicate that $\mathbf{C}_{2}-\mathrm{C}_{6}$ organic nitrates contribute only a small fraction (in this case, $2.5-3 \%$ ) to $\mathrm{NO}_{\mathrm{y}}$.
Although the multifunctional organic nitrates were found in small concentrations, they may provide a more efficient means of removal of $\mathrm{NO}_{\mathrm{x}}$ from the atmosphere due to the fact that their dry and wet deposition rates are likely to be much greater than for the simple alkyl nitrates. This is likely to be true for the isoprene nitrates as well, and given the magnitude of the estimated formation yield, isoprene nitrate formation may be an effective route for the removal of $\mathrm{NO}_{\mathbf{x}}$ from a reactive air mass. However, the formation yield $\left(k_{1 b} / k_{1}\right)$ has not been directly measured, nor have these species ever been detected in atmospheric samples. It is possible that the isoprene nitrates and other multifunctional organic nitrates, e.g., those produced from $\mathrm{OH}$ reaction with terpenes, may be partitioned to a significant extent in the aerosol phase. Analytical methods thus need to be developed to enable quantitative determination of aerosol-bound organic nitrates. It is thus clear that more work is necessary to elucidate the role of these organic nitrates in the chemistry of atmospheric nitrogen.

Acknowledgments. We thank the Ontario Ministry of the Environment and Energy for their support of this work, and W. Moroz for his assistance with the field site. This is publication number 94-8 of the Canadian Institute for Research in Atmospheric Chemistry (CIRAC).

\section{References}

Atkinson, R., Kinetics and mechanisms of the gas phase reactions of the hydroxyl radical with organic compounds under atmospheric conditions, Chem. Rev., 86, 69-201, 1986

Atkinson, R., A structure-activity relationship for the estimation of rate constants for the gas-phase reactions of $\mathrm{OH}$ radicals with organic compounds, Int. J. Chem. Kinet., 19, 799-828, 1987.

Atkinson, R., Kinetics and mechanisms of the gas phase reactions of the hydroxyl radical with organic compounds, J. Phys. Chem. Ref. Data, Monogr. 1, 1989.

Atkinson, R., and W. P. L. Carter, Reactions of alkoxy radicals under atmospheric conditions: The relative importance of decomposition versus reaction with $\mathrm{O}_{2}$, J. Atmos. Chem., 13, 195-210, 1991.

Atlas, E., Evidence for $\geq C_{3}$ alkyl nitrates in rural and remote atmospheres, Nature, 331, 426-428, 1988.

Atlas, E., and S. Schauffler, Analysis of alkyl nitrates and selected halocarbons in the ambient atmosphere using a charcoal preconcentration technique, Environ. Sci. Technol., 25, 61-67, 1991.

Atlas, E., B. A. Ridley, G. Hübler, J. G. Walega, M. A. Carroll, D. D. Montzka, B. J. Huebert, R. B. Norton, F. E. Grahek, and S. Schaufler, Partitioning and budegt of $\mathrm{NO}_{y}$ species during the Mauna Loa Observatory Photochemistry Experiment, J. Geophys. Res., 97, 10,449-10,462, 1992a.

Atlas, E., S. M. Schauffler, J. T. Merrill, C. J. Hahn, B. Ridley, J. Walega, J. Greenberg, L. Heidt, and P. Zimmerman, Alkyl nitrate and selected halocarbon measurements at Mauna Loa Observatory, Hawaii, J. Geophys. Res., 97, 10,331-10,348, 1992 b.

Buhr, M. P., D. D. Parrish, R. B. Norton, F. C. Fehsenfeld, R. E. Sievers, and J. M. Roberts, Contribution of organic nitrates to the total reactive nitrogen budget at a rural eastem U.S. site, $J$. Geophys. Res., 95, 9809-9816, 1990.

Carter, W. P. L., and R. Atkinson, Alkyl nitrate formation from the atmospheric photooxidation of alkanes: A revised estimation method, J. Atmos. Chem., 8, 165-173, 1989.

Fahey, D. W., G. Hübler, D. D. Parrish, E. J. Williams, R. B. Norton, B. A. Ridley, H. B. Singh, S. C. Liu, and F. C. Fehsenfeld, Reactive nitrogen species in the troposphere: measurements of NO, $\mathrm{NO}_{2}, \mathrm{HNO}_{3}$, particulate nitrate, peroxyacetyl nitrate (PAN), $\mathrm{O}_{3}$, and total reactive nitrogen (NO ${ }_{y}$ ) at Niwot Ridge, Colorado, $J$. Geophys. Res., 91, 9781-9793, 1986.

Flocke, F., A. Volz-Thomas, and D. Kley, Measurements of alkyl nitrates in rural and polluted air masses, Atmos. Environ., 25A, 1951-1960, 1991.

Flocke, F., A. Volz-Thomas, and D. Kley, The use of alkyl nitrate 
measurements for the characterization of the ozone balance in southwestem Germany, EOS Trans. $A G U, 74$ (43), Fall Meet. Suppl., 180, 1993.

Grosjean, D., Distribution of atmospheric nitrogenous pollutants at a Los Angeles area smog receptor site, Environ. Sci. Technol., 17, 13-19, 1983.

Hao, C., P. B. Shepson, J. W. Drummond, and K. Muthuramu, Development of a gas chromatographic detector for selective and sensitive detection of atmospheric organic nitrates, Anal. Chem., $66,3737-3743,1994$.

Hastie, D. R., P. B. Shepson, N. W. Reid, P. B. Roussel, and O. T. Melo, Summertime $\mathrm{NO}_{\mathrm{x}}, \mathrm{NO}_{\mathrm{y}}$ and ozone at a site in rural Ontario: Results from SONTOS, Atmos. Environ., in press 1995.

Kames, J., and U. Schurath, Alkyl nitrates and bifunctional nitrates of atmospheric importance: Henry's law constants and their temperature dependencies, J. Atmos. Chem., 15, 79-95, 1992.

Muthuramu, K., P. B. Shepson, and J. M. O'Brien, Preparation, analysis and atmospheric production of multifunctional organic nitrates, Environ. Sci. Technol., 27, 1117-1124, 1993.

Parrish, D. D., et al., Total reactive oxidized nitrogen levels and the partitioning between the individual species at six rural sites in eastem North America, J. Geophys. Res., 98, 2927-2939, 1993.

Plummer, D., J. C. McConnell, P. B. Shepson, D. R. Hastie, and H. Niki, Modeling of ozone formation at a rural site in southern Ontario, Atmos. Environ., in press, 1995.

Reid, N. W., et al., The Southem Ontario Oxidant Study (SONTOS): Overview and case studies for 1992, Almos. Environ., in press, 1995.

Ridley, B. A., Recent measurements of oxidized nitrogen compounds in the troposphere, Atmos. Environ., 25A(9), 1905-1926, 1991.

Ridley, B. A., J. D. Shetter, J. G. Walega, S. Madronich, C. M. Elsworth, and F. E. Grahek. The behaviour of some organic nitrates at Boulder and Niwot Ridge, Colorado, J. Geophys. Res., 95, 13,949-13,961, 1990.

Ridley, B. A., S. Madronich, R. B. Chatfield, J. G. Walega, R. E. Shetter, M. A. Carroll, and D. D. Montzka, Measurements and model simulations of the photostationary state during the Mauna
Loa Observatory Photochemistry Experiment: Implications for radical concentrations and ozone production and loss rates, $J$. Geophys. Res., 97, 10,375-10,388, 1992.

Roberts, J. M., Review article: The atmospheric chemistry of organic nitrates, Atmos. Environ., $24 A$ (2), 243-287, 1990.

Shepson, P. B., E. O. Edney, T. E. Kleindienst, J. H. Pittman, G. R. Namie, and L. T. Cupitt, The production of organic nitrates from hydroxyl and nitrate radical reaction with propylene, Environ. Sci. Technol., 19, 849-854, 1985.

Shepson, P. B., D.R. Hastie, K.W. So, H.I. Schiff, and P. Wong, Relationships between PAN, PPN, and $\mathrm{O}_{3}$ at urban and rural sites in Ontario, Almos. Environ., 26A, 1259-1270, 1992.

Shepson, P. B., K. G. Anlauf, J. W. Bottenheim, H. A. Wiebe, N. Gao, K. Muthuramu, and G. I. Mackay, Alkyl nitrates and their contribution to reactive nitrogen at a rural site in Ontario, Atmos. Environ., $27 A$ (5), 749-757, 1993.

Stockwell, W. R., P. Middleton, J. S. Chang, and X. Tang, The second generation regional acid deposition model chemical mechanism for regional air quality modeling, $J$. Geophys. Res., 95, 16,343$16,367,1990$.

Tuazon, E. C., and R. Atkinson, A product study of the gas-phase reaction of isoprene with the $\mathrm{OH}$ radical in the presence of $\mathrm{NO}_{x}$, Int. J. Chem. Kinet., 22, 1221-1236, 1990.

C. Hao, D. R. Hastie, K. Muthuramu, H. Niki, and J. M. O'Brien, Department of Chemistry and Centre for Atmospheric Chemistry, York University, 4700 Keele Street, North York, Ontario, Canada M3J 1 P3.

P. B. Roussel and R. Taylor, Ontario Hydro, Research Division, 800 Kipling Ave., Toronto, Ontario, Canada M8Z $5 S 4$.

P. B. Shepson (corresponding author), Departments of Chemistry and Earth and Atmospheric Sciences, Purdue University, 1393 Brown Building, West Lafayette, Indiana 47907-1393.

(Received March 21, 1994; revised September 29, 1994; accepted December 2, 1994.) 